\title{
AN ANALYSIS OF THE STUDY PLAN OF THE PROFESSIONALLY ORIENTED BACHELOR STUDY FIELD OF MULTIMEDIA IN ECONOMIC PRACTISE
}

\author{
Zdeněk Vondra, Kristýna Vltavská
}

University of Economics, Prague

\author{
Highlights \\ - If a course is popular by its contents students find the course more relevant to prospective jobs
}

\begin{abstract}
This paper focuses on the study field of Multimedia in Economic Practise which has been taught at the University of Economics in Prague since 2011. This study field has its first graduates which is the reason for a re-examination of the profile of graduates according to the structure of subjects in the study plan. This paper describes evolution of the study field, its content, main idea and structure of its students. It presents two main groups of occupations for graduates with dependence on requirements for student's additional independent activities beyond the study. The analytical part shows five examples of comparison of the course relevance according to the opinion of students and academic staff. The conclusions from the survey will enable academic staff of the study field to the reconsider the future development of the study field.
\end{abstract}

\section{Keywords}

Economic practice, education, multimedia, students' opinions
Article type

Full research paper

Article history

Received: December 1, 2014

Received in revised

form: December 28, 2014

Accepted: December 29, 2014

Available on-line: December 31, 2015

Vondra Z. and Vltavská K. (2014) "An Analysis of the Study Plan of the Professionally Oriented Bachelor Study Field of Multimedia in Economic Practice", Journal on Efficiency and Responsibility in Education and Science, Vol. 7, No. 3-4, pp. 74-79, online ISSN 1803-1617, printed ISSN 1803-1617, doi: 10.7160/eriesj.2014.070305.

\section{Introduction}

The bachelor study field of Multimedia in Economic Practice was being prepared at the Faculty of Informatics and Statistics at the University of Economics in Prague after 2009 and it was accredited in the summer of 2011. In September 2011, first students were admitted to the study. A significant part of students graduated in June 2014 as the first graduates of this field ever. The study field is accredited within the study program of Applied Informatics. This establishment is based on the principle that the creation of multimedia is perceived as the creation of communication tools. It means encoding of information, messages and knowledge. This theoretical approach is applied and used as a basic tool for the explanation of the principles. The principles used in teaching of Multimedia in Economic Practice are based on theory of multimedia learning (Mayer, 2009, Mayer and Moreno, 2003), theory of communication (Craig, 1997, Rothwell, 2009) including dual coding theory (Paivio, 1986) and multimedia practical description (Vaughan, 2008).

The moment just after graduating of the first full run of the study field is an opportunity for a review and verification of reaching the goals and expectations of the study field creators ${ }^{1}$ (author is one of creators and member of academic staff of this study field) and teachers focused on future students' occupation.

In this paper, we verify whether Multimedia in Economic Practice effectively meets their professional status. It means whether a student is ready for entering into practice immediately after the bachelor level of study. This verification process should answer the question what knowledge and skills are actually missing in the program and which are unnecessary. Areas of knowledge and skills that students should acquire and operate are reflected in the construction of the study plan, which was

The verification of the fulfilling the expectation on the level of individual subject was discussed in Krejčí et. al. (2011). carefully compiled in relation to the current requirements of practice and expert advices. Therefore, we verify whether the actual setting fits the vision of future knowledge and skills of graduates. This knowledge and skills should be completed for the selected occupation profiles that the creators of the study field set as the goal at the beginning of the formulation. At first, we surveyed university data and thereafter we prepared a survey among students asking for their opinion of the courses, their future occupation and relevant practice. Based on the results we can analyse which courses in the study field are more and less useful or completely useless for a future student's occupation. Moreover, we investigate whether students are motivated to continue their studies at any of the similar or different master study programs. This paper follows and elaborates the findings of Vondra and Vltavská (2014).

\section{Motivation to form the study field}

The motivation for the development of the study field was based on public demand among university students, secondary school graduates and employers. This trend relates to digitalization and subsequent availability of multimedia resources to a wide range of users. Herewith, multimedia, which used to represent a closed area of a narrow group of professionals equipped with financially demanding resources, opened towards participation of a wider group including semi-professionals and amateurs. They now face a substantially lower barrier to their use or input into the production of multimedia communications.

The requirements of employers came especially from the field of advertising agencies and companies operating television or radio broadcasts. Their demand has defined the need for new specialists able to work and understand various different types of multimedia tools at the same time. In context with savings and production efficiency, the overlap is a competitive advantage and 
enables flexibility of both the worker and the organization that employs them. This fact was confirmed by associate teachers of journalism at the Faculty of Social Sciences, Charles University who observed the trend that a reporter due to attempts on saving is forced to operate both the camera and video production and post-production process.

\section{Study plan and profile of the graduate}

Multimedia in Economic Practice teaches information especially in the areas of analysis, conception, design and processing of multimedia content for the realization of functional communication. The study field is based on soft systems methodology and theories of information, communication, knowledge, and multimedia learning. It hereby defines procedures for effective multimedia production. From the point of view of specific implementation multimedia is further taught according to practices of each sub-area (typography and word processing, graphics, photographs, video, sound, animation).

Graduates are able to analyse the communication objectives of the company and to propose appropriate usage of multimedia (VŠE, 2011). That means creatively design, implement, or provide various multimedia tools for the specific needs of corporate communication. Graduates are be able to implement these tools either on their own or competently choose an outsourced company and judge the suitability and quality of the selected solution afterwards. This general description is explained by the overview of the study plan and a list of professions, which aspire to their working life.

\section{Expected occupation of a graduate}

A graduate can find employment in management and administration. If a graduate tends deeply to one of the specific multimedia disciplines they have a chance to become a professional in the field with knowledge overlapping to other related areas. In practice, the graduate and their work will be more flexible and independent from the structure of the organization or subcontractors. We revised the list of examples of positions from the profile of graduates (VŠE, 2011) and we divided the list in two groups depending on how much personal effort beyond studies is required.

Occupations performance, which does not require student's additional independent activities beyond the study:

- Account Executive, Account Manager (project manager at an advertising agency)

- Marketer, buyer, project manager or PR client-side communication expert

- Strategic / media planner for communication campaigns

- $\quad$ Project manager, executive producer, production manager in advertising, production and post-production companies

- Production manager ensuring realization of multimedia work, runner director

- Creative, art director, creative director, idea maker (creator and creative concepts processor)

- Processor of internal corporate multimedia (photo and video documentation, creating simple graphics)

- Webmaster

Occupations performance, which requires student's personal interest and work beyond the study:

- 2D / 3D graphics maker (creator and processor of graphic design, visualization)

- $2 \mathrm{D} / 3 \mathrm{D}$ graphics animator (creator processor and graphic jingles for video, animated commercials or basic visual effects)

- $\quad$ Typesetting of documents, printed or outdoor advertising (processor of text, graphics and photos)

- Graphics and typesetting maker for the digital environment (banners, websites, social networks)

- Reporting, product or advertising photographer

- Digital video production maker or assistant, occupant in television or movie companies

- Web designer, director and evaluator of websites

- Audio production and post-production company or advertising or recording studios occupant

- Multimedia journalist in the service of the company or other organization (internet portal, government, local cable TV)

- Coder and programmer of the website or user interface programs and applications (requires completion of education in programming)

\section{Materials and Methods}

The aim of the survey was the examination of the meaningfulness and structure of courses taught in relation to the prospective profession of graduates, their previous experience and success in their studies. We acquired 71 answers from the survey from which $51 \%$ represents male students and $49 \%$ represents female students. $59 \%$ of students involved in the survey already had some work experiences in the jobs related to the studies.

As we mentioned in previous chapter graduates can be employed in different types of occupation related to the multimedia. We distinguished these occupations into 11 groups according to the content of the future job:

1. MARK - Account Executive, Account Manager; Marketer, buyer, project manager or PR client-side communication expert

2. STRAT - Strategic/media planner for communication campaigns; Project manager, executive producer, production manager in advertising, production and postproduction companies

3. CREAT - Creative, art director, creative director, idea maker

4. PROD - Production manager ensuring realization of multimedia work, runner director

5. INHOUSE - Processor of internal corporate multimedia

6. ANIM - 2D / 3D graphics maker, 2D / 3D graphics animator

7. GRP - Typesetting of documents, printed or outdoor advertising; Graphics and typesetting maker for the digital environment

8. PHOTO - Reporting, product or advertising photographer; Multimedia journalist in the service of the company or other organization

9. VIDEO - Digital video production maker or assistant, occupant in television or movie companies

10. SOUND - Audio production and post-production company or advertising or recording studios occupant

11. WEB - Webmaster; Web designer, director and evaluator of websites; Coder and programmer of the website or user interface programs and applications

For the purpose of this paper we chose 5 different future occupations from these groups which represented different work positions and different opinions of the students. Results are based 
on the comparison of the students' and academic staffs' opinions of the relevance of subjects contained in the study plan. The questionnaire contains questions about the students' opinions of the relevance of all obligatory subjects from the study plan. As one of the authors is the creator of the study field and member of academic staff, his opinion on the relevance of the subjects for different occupation groups was used (see Appendix to find the relevance of subject of 11 occupational groups as rated by academic staff). We state 5 as the most relevant and 1 as irrelevant. Figures 1 to 5 contain mean values for each subject.

\section{Results and Discussion}

The first group (Fig. 1) describes the most wanted job among students. However, not everyone can do that. This occupation is based on very deep professional and personal skills. One can see that the opinion on subjects relevance of academic staff of the study field copy the opinion of students. Only exceptions represent subjects Cultural Politics, Local and Regional Culture and History of Art and Modes of Aesthetic Experience. As these two courses are very descriptive and students are mostly creative, they do not consider subjects as relevant. Conventional students' approach is that they want to create (learn by doing), rather than to passively learn (in terms of declarative knowledge gaining).

In the case of Cultural Politics, Local and Regional Culture, creators of study field and teacher of the course concluded that this course is not perfectly suitable for the study field. Its function was to establish the point of view on media including the regional and cultural aspects. The malfunction occurred because of its strong focusing on material cultural heritage and its animation. It did not come as essential information for multimedia creation. A discussion had started about superseding it by course Local and regional sociology, which reflects the human behaviour in connection with geography more.

In the case of the course History of Art and Modes of Aesthetic Experience, academic staff of the study field found that students' perspective of creational processes in past should work as the essential best practices. We can admit that this kind of course may be unpopular because of its descriptive style of historical content and because of implemented philosophy part about working of aesthetics but unpopularity does not mean irrelevancy.

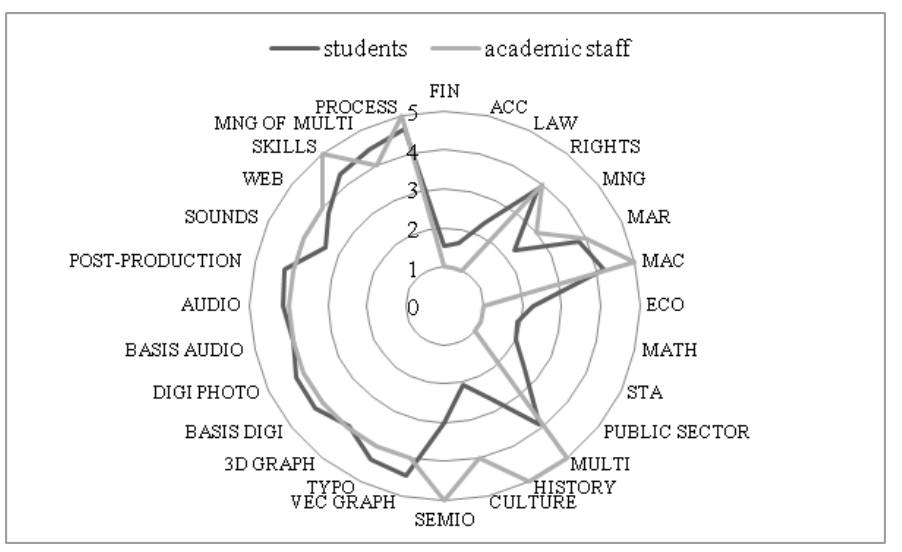

Fig. 1: Creative, art director, creative director, idea maker (creator and creative concepts processor)

Source: Vondra, Vltavská (2014)

Note: FIN - Corporate Finance, ACC - Accounting, LAW - Law, RIGHTS Copyright and Industrial Property Rights, MNG - Management, MAR Marketing, MAC - Marketing Communications, ECO - Economics, MATH Mathematics for Economists, STA - Statistics, PUBLIC SECTOR - Public Sector and Financing in Area of Multimedia, MULTI - Introduction to Multimedia
Theory, HISTORY - History of Art and Modes of Aesthetic Experience, CULTURE - Cultural Politics, Local and Regional Culture, SEMIO - Multimedia Semiotics, VEC GRAPH - Basics and Applications of Vector Graph, TYPO Computer Typography and Typesetting, 3D GRAPH - Applications of 3D Graphics, BASIS DIGI - Basics of Digital Photography and Editing Bitmap, DIGI PHOTO - Digital Photography and Bitmap Editing, BASIS AUDIO Basics of Audiovisual Communication, AUDIO - Audiovisual Communication, POST-PRODUCTION - Audiovisual Post-production, SOUNDS - Sound and Multimedia, WEB - Web Design and User Interfaces, SKILLS - Presentation Skills, MNG OF MULTI - Management of Multimedia Projects, PROCESS Communication and Creative Processes

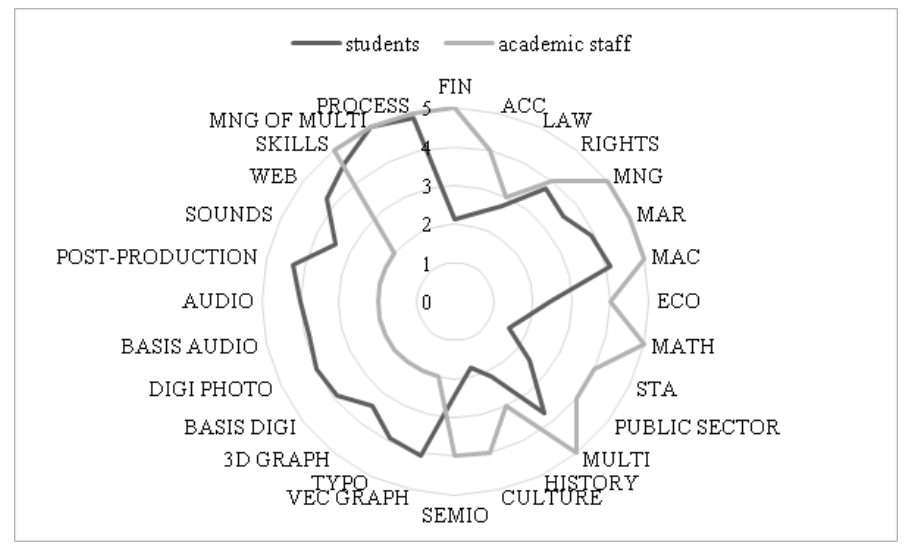

\section{Fig. 2: Project manager, executive producer, production manager in advertising, production and post-production companies}

Figure 2 shows that there is lesser agreement between students and academic staff about the relevance of the subjects included in the study plan. The disagreement lies mainly in creative subjects where academic staffs' requirements contain only the knowledge about instruments without deeper creative knowledge. The explanation could be found in the overall popularity of creative courses which evokes the feel of relevance among the students. Economic and theoretical oriented courses are undervalued by students.

However, Figure 2 also shows the same understanding of the necessity of the subjects by students and academic staff. The lower relevance level corresponds with the lesser popularity of theoretical subjects among students. Great paradox, but a reaffirmation of the impact of the level of complexity of the conceptual issues, represents course Multimedia Semiotics. There is a completely opposite assessment. This course examines the processes of perception and interpretation. The intention was to provide academic staff a tool for deeper knowledge assessment for evaluating the submitted work creative professions. This course stands at the border of Master's and Bachelor's degree and requires concentration and understanding, which in the context of the study field discourage students. The output of the findings from the Figure 2 presents the necessity of a more rigorous explanation of the importance of theoretical courses within the context of the study field. On the other hand, theoretically oriented courses should be reviewed in terms of their contribution, whether they actually fulfil their function.

Figure 3 describes the agreement of students' and academic staffs' opinions with some significant deviations. Very interesting agreement or higher relevance according to students was found among the economical courses (excluding Mathematics). However, Mathematics represents a crucial element in 3D graphics. Its low rating can be caused by the amount of theory taught and the difficulty of the subject since the success of study of this course is around 70\% (in comparison with high level of success of creative subjects - $85 \%$ to $98 \%$ ). Theoretical courses again show the same trend of proving less relevance 
for the students. Professional practical courses - the courses that teach the specific issues - gained interesting evaluation. These courses only scored $4 / 5$. In contrast, the other courses which are complementary for the profession have nearly the same relevance, including Sound and Multimedia, which is practically unusable for static graphics. Students clearly perceive the overlap of this group of profession which indicates their desire and interest in the multidisciplinary principle of the study field. Courses such as Presentation Skills and Management of Multimedia Projects seem to be very relevant, even though their meaning may be used more in professions that are in contact with customers and the market. The explanation is again in the interest of students in practical courses.

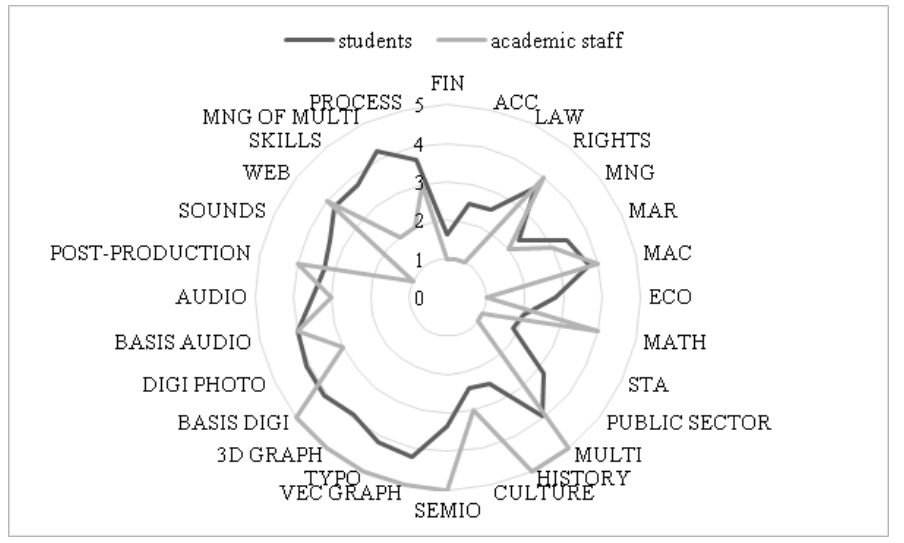

Fig. 3: 2D / 3D graphics maker (creator and processor of graphic design, visualization)

Due to the similarity of the results, Figure 4 and Figure 5 are discussed at once. In terms of economic courses there is agreement between students and academic staff. The founding about other areas follow the same pattern as the previous examples. For theoretical courses there are less relevance ratings from students, but values copy mutual ratio among academic staff. For practical courses follow the trend of balancing relevance across the multimedia fields without the detailed reflection of a specific profession. In Figure 4 it is worth mentioning again highlighted the relevance of course Sound and Multimedia by students in the context of the creation of digital photos. In case of Figure 5 it is a designation of Basics and Applications of Vector Graphics and Computer Typography and Typesetting.

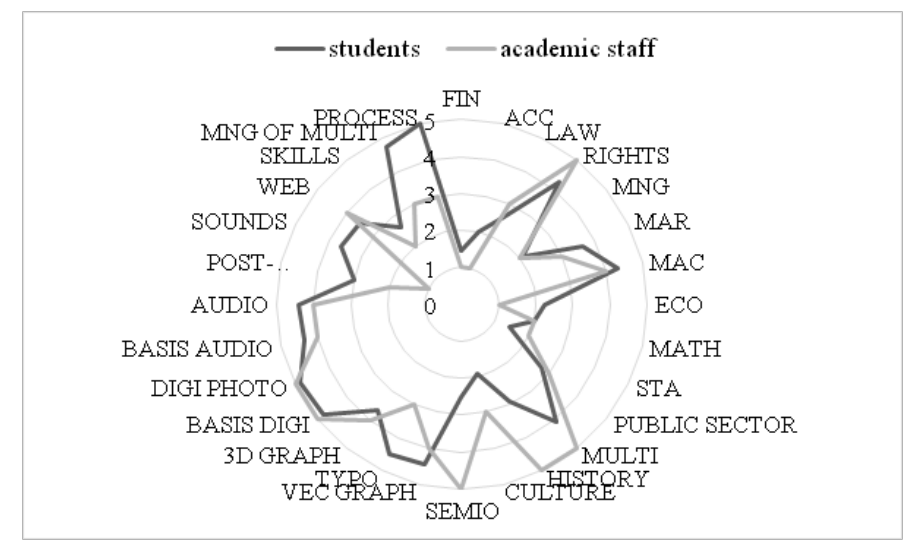

Fig. 4: Reporting, product or advertising photographer

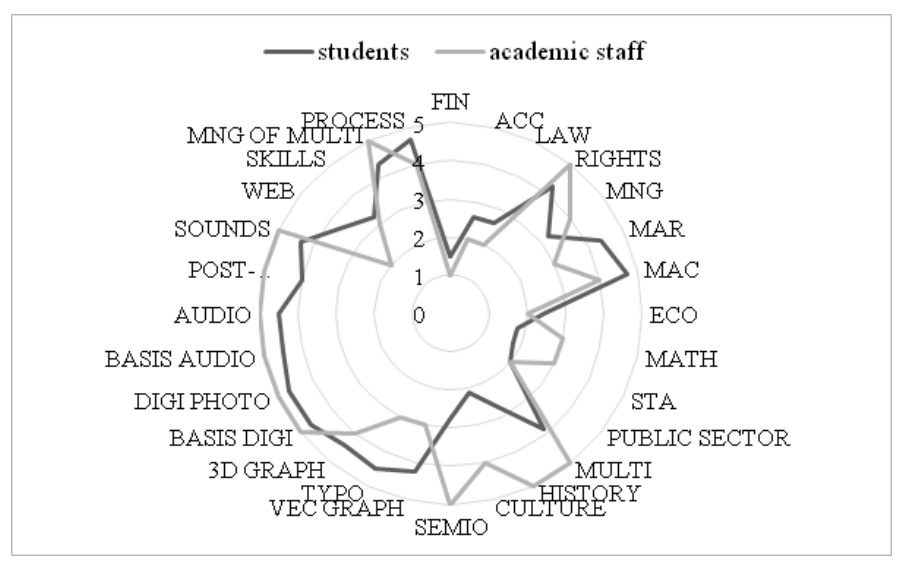

Fig. 5: Digital video production maker or assistant, occupant in television or movie companies

Kučera et al. (2012) and Kučera et al. (2013) investigated how the changes in accreditation of the subject of Mathematical Methods in Economics II influenced the results of students' success in the first and in the second year after these changes. Krejčí et al. (2011) focused on the description of the students' opinions on the changes in the subject of Mathematical Methods in Economics using system dynamics. The authors used questionnaire to find out students' opinions on the possibility to integrate the system dynamics into the study. On the other hand, this paper surveyed opinions of student on the whole concept of the study field of Multimedia in Economic Practise. Members of academic staff wanted to create a study field which fulfils not only the requirements of prospective employers. This survey served as a source of information for academic staff whether students understood the importance of the content of each part of the study field in accordance to their future job.

Results of the survey show that the profile of a graduate (V ̌̌E, 2011) requires a modification. In particular, an alteration of the structure of courses which fulfil the profile is necessary. Results of the survey demonstrated that better students' knowledgeableness of the core of less popular courses needs to be ensured. The generally relevant courses should implement the intersections with various areas into other courses. Students ought to understand the courses' importance, usefulness and see their interconnection. Creators of the study field want to increase the intensity of the analytical subjects (e.g. Statistics, Demography). As we already mentioned, the substitutions of some courses are important. Students pointed out that the course of Cultural Politics, Local and Regional Culture is irrelevant to their study field. Since the creators have no arguments for retaining this course in the study plan (VŠE, 2011) this subject will be replaced by the course of Local and Regional Sociology in the new accreditation. Moreover, courses focusing on the language skills and work with text materials will be added to the study plan (e.g. Creative writing 2.0). The final important finding represents the students' willingness to combine different multimedia fields. This is confirmed by the trend of assigning tasks, which expect the students to draw not only from a narrow specialized field but from various areas of multimedia simultaneously (e.g. in the course of Sound and Multimedia the visual part of the task, which relates to and develops the sound record, has to be submitted as well).

\section{Conclusion}

Every creator of the study field wants to design the study plan that fulfils the requirements of future employers of the graduates and in the same way that accomplishes the expectation of 
students. As the first graduates of the Multimedia in Economic Practise study field will look for jobs according their knowledge academic staff of the study field wanted to find out if their study plan was built in relevance to the students and their expectations. The analysis of the relevance of the courses in context of the future jobs of the graduates of professionally oriented study field Multimedia in Economic Practise shows several repeated situations which presents the input for the conceptual changes of the courses. There exist different views on the relevance of the theoretical courses. Students evaluate them as less relevant in comparison with the opinion of academic staff. This leads to the revision of courses' content and integration to the study plan (e.g. course Introduction to Multimedia Theory was renovated for the academic year 2014/2015 according to the founding from the survey).

From the results of the survey within students of the study field we found out that (in general) if a course is popular by its contents students find the course more relevant to their prospective professions without connection to occupation requirements for skills and knowledge. On the contrary, if a course is not very popular among students they marked it as irrelevant. Course focused on culture studies provided by Department of Arts Management was found irrelevant by students. After the discussion with its teacher we decided to remove this course from the study plan in next accreditation. Conceptual oriented courses are hard to get for students as they are used to learn practical skills. It is necessary to bring conceptual courses close to the practice.

Academic staff of the Multimedia in Economic Practise study field plan to prepare this survey again at the end of the academic year $2014 / 2015$. At that time there will be not only new graduates but the first graduates will have finished their first year at work. Through the contact between academic staff and graduates we will be able to verify what type of occupation they work at and what their opinions on the relevance of the subjects are after one year in practise.

\section{Acknowledgements}

This article is supported by Institutional Support for Long Period and Conceptual Development of Research and Science at Faculty of Informatics and Statistics, University of Economics, Prague.

\section{References}

Craig, R. T. (1997) 'Communication theory as a Field', Communication Theory, vol. 9, no. 2, pp. 119-161. http://dx.doi. org/10.1111/j.1468-2885.1999.tb00355.x.

Krejčí, I., Kvasnička, R., Dömeová, L. (2011) 'Introducing System Dynamics at CULS Prague', Journal on Efficiency and Responsibility in Education and Science, Vol. 4, No. 4, pp. $187-$ 196.

Kučera, P., Kvasnička R., Krejčí, I. (2012) 'Impact of the contact teaching reduction on study results in the course of Mathematical methods in economics II', Proceedings of the 9th International Conference on Efficiency and Responsibility in Education (ERIE 2012), Prague, pp. 287-293.

Kučera, P., Kvasnička, R., Vostrá Vydrová, H. (2013) 'Study results development in mathematical methods in economics in two years from accreditation', Proceedings of the 10th International Conference on Efficiency and Responsibility in Education (ERIE 2013), Prague, pp. 341-346.
Mayer, R.E., Moreno, R. (2003) 'Nine ways to reduce cognitive load in multimedia learning', Educational Psychologist, vol. 38, no. 1,pp.43-52.http://dx.doi.org/10.1207/S15326985EP3801_6. Mayer, R. E. (2009) Multimedia learning. 2nd ed. Cambridge: Cambridge University Press.

Paivio, A. (1986). Mental representations: a dual coding approach. Oxford, England: Oxford University Press.

Rothwell, J. D. (2009) In the company of others: an introduction to communication. New York: Oxford University Press.

University of Economics in Prague (VŠE), (2011) Profile of a graduate (in Czech only), Praha. [Online], Available: http://gml. vse.cz/zajemci-o-studium/profil-absolventa/. [3 May 2014].

Vaughan, T. (2008) Multimedia: making it work. 7th ed. New York: McGraw-Hill.

Vondra, Z., Vltavská, K. (2014) 'Revision of Course Settings in Multimedia in Economic Practice Study Field', Proceedings of the 11th International Conference on Efficiency and Responsibility in Education (ERIE 2014), Prague, pp. 898-904. 


\section{Appendix}

Table 1: Study plan and the relevance of subjects towards 11 groups of occupation by academic staff

\begin{tabular}{|c|c|c|c|c|c|c|c|c|c|c|c|}
\hline Subject/group of occupation & 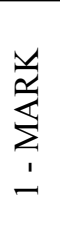 & 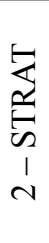 & 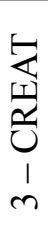 & $\begin{array}{c}\hat{0} \\
\frac{\alpha}{2} \\
\dot{v}\end{array}$ & 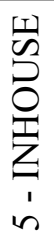 & 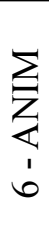 & $\frac{a}{0}$ & $\begin{array}{c}0 \\
\stackrel{0}{0} \\
\frac{1}{0} \\
1 \\
\infty\end{array}$ & 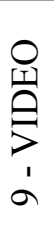 & $\begin{array}{l}\hat{Z} \\
\vdots \\
0 \\
\infty \\
1 \\
0\end{array}$ & $\begin{array}{l}\frac{m}{3} \\
\frac{1}{3} \\
=\end{array}$ \\
\hline Corporate Finance & 4 & 5 & 1 & 4 & 3 & 1 & 1 & 1 & 1 & 1 & 1 \\
\hline Accounting & 3 & 4 & 1 & 5 & 2 & 1 & 1 & 1 & 2 & 2 & 1 \\
\hline Law & 4 & 3 & 1 & 4 & 4 & 1 & 1 & 3 & 2 & 2 & 4 \\
\hline Copyright and Industrial Property Rights & 5 & 4 & 4 & 4 & 5 & 4 & 4 & 5 & 5 & 5 & 5 \\
\hline Management & 5 & 5 & 3 & 5 & 3 & 2 & 2 & 2 & 4 & 4 & 4 \\
\hline Marketing & 5 & 5 & 4 & 5 & 3 & 3 & 3 & 3 & 3 & 3 & 3 \\
\hline Marketing Communications & 5 & 5 & 5 & 5 & 4 & 4 & 4 & 4 & 4 & 4 & 5 \\
\hline Economics & 3 & 4 & 1 & 5 & 3 & 1 & 1 & 1 & 2 & 2 & 2 \\
\hline Mathematics for Economists & 3 & 5 & 1 & 4 & 2 & 4 & 3 & 2 & 3 & 3 & 4 \\
\hline Statistics & 4 & 4 & 1 & 4 & 2 & 1 & 2 & 2 & 3 & 3 & 5 \\
\hline Public Sector and Financing in area od Multimedia & 5 & 4 & 1 & 5 & 2 & 1 & 1 & 3 & 2 & 2 & 3 \\
\hline Introduction to Multimedia Theory & 5 & 5 & 5 & 4 & 5 & 5 & 5 & 5 & 5 & 5 & 5 \\
\hline History of Art and Modes of Aesthetic Experience & 2 & 3 & 5 & 2 & 4 & 5 & 5 & 5 & 5 & 5 & 5 \\
\hline Cultural Politics, Local and Regional Culture & 2 & 4 & 4 & 3 & 4 & 3 & 2 & 3 & 4 & 4 & 4 \\
\hline Multimedia Semiotics & 2 & 4 & 5 & 3 & 4 & 5 & 5 & 5 & 5 & 5 & 5 \\
\hline Basics and Applications of Vector Graph & 2 & 2 & 4 & 2 & 4 & 5 & 5 & 4 & 3 & 1 & 4 \\
\hline Computer Typography and Typesetting & 2 & 2 & 4 & 2 & 4 & 5 & 5 & 3 & 3 & 1 & 5 \\
\hline Applications of 3D Graphics & 2 & 2 & 4 & 2 & 3 & 5 & 4 & 4 & 4 & 1 & 3 \\
\hline Basics of Digital Photography and Editing Bitmap & 2 & 2 & 4 & 2 & 5 & 5 & 5 & 5 & 5 & 1 & 3 \\
\hline Digital Photography and Bitmap Editing & 2 & 2 & 4 & 2 & 4 & 3 & 5 & 5 & 5 & 1 & 3 \\
\hline Basics of Audiovisual Communication & 2 & 2 & 4 & 2 & 5 & 4 & 3 & 4 & 5 & 4 & 3 \\
\hline Audiovisual Communication & 2 & 2 & 4 & 2 & 4 & 3 & 2 & 4 & 5 & 4 & 3 \\
\hline Audiovisual Post-production & 2 & 2 & 4 & 2 & 3 & 4 & 2 & 2 & 5 & 5 & 2 \\
\hline Sound and Multimedia & 2 & 2 & 4 & 2 & 4 & 1 & 1 & 1 & 5 & 5 & 3 \\
\hline Web Design and User Interfaces & 2 & 2 & 4 & 2 & 3 & 4 & 4 & 4 & 2 & 2 & 5 \\
\hline Presentation Skills & 5 & 5 & 5 & 5 & 4 & 2 & 2 & 2 & 3 & 2 & 3 \\
\hline Management of Multimedia Projects & 5 & 5 & 4 & 5 & 4 & 2 & 3 & 3 & 5 & 5 & 4 \\
\hline Communication and Creative Processes & 5 & 5 & 5 & 4 & 4 & 3 & 3 & 3 & 4 & 3 & 5 \\
\hline
\end{tabular}

Note: $5=$ the most relevant, $1=$ irrelevant 